\title{
Evaluation of psoriasis patients' attitudes toward benefit-risk and therapeutic trade-offs in their choice of treatments
}

This article was published in the following Dove Press journal:

Patient Preference and Adherence

28 February 2017

Number of times this article has been viewed

\author{
Lina Eliasson' \\ Anthony P Bewley ${ }^{2}$ \\ Farhan Mughal ${ }^{3}$ \\ Karissa M Johnston ${ }^{4}$ \\ Andreas Kuznik ${ }^{5}$ \\ Chloe Patel' \\ Andrew J Lloyd' \\ 'Clinical Outcomes Assessment, \\ ICON Clinical Research UK Ltd, \\ ${ }^{2}$ Department of Dermatology, Whipps \\ Cross University Hospital, Barts \\ Health National Health Service \\ Trust, London, ${ }^{3} \mathrm{Health}$ Economics \\ Outcomes Research, Celgene Ltd, \\ Uxbridge, UK; ${ }^{4}$ Epidemiology, ICON \\ Commercialisation and Outcomes, \\ Vancouver, BC, Canada; ${ }^{5}$ Global Health \\ Economics and Outcomes Research, \\ Celgene Corporation, Summit, NJ, USA
}

Correspondence: Lina Eliasson Clinical Outcomes Assessment, ICON Clinical Research UK Ltd, 22 Tudor Street, 2nd Floor, London EC4Y OAY, UK $\mathrm{Tel}+4420$ I86 5320142 Fax +44202031946619 Email lina.eliasson@iconplc.com
Objective: Treatment options for psoriasis offer trade-offs in terms of efficacy, convenience, and risk of adverse events. We evaluated patients' preferences with respect to benefit-risk in the treatment of psoriasis.

Methods: A discrete choice experiment was conducted in adults from the UK with moderateto-severe psoriasis using an orthogonal design with 32 hypothetical choice sets. Participants were randomly assigned to one of two surveys with 16 choice sets. Patients' preferences were investigated with respect to the following attributes: reduction in body surface area affected by psoriasis, treatment administration (frequency and mode of delivery), short-term diarrhea or nausea risk, and 10-year risk of developing melanoma or nonmelanoma skin cancer, tuberculosis, or serious infections. A mixed effects logistic regression model generated relative preferences between treatment profiles.

Results: Participants ( $\mathrm{N}=292)$ had a strong preference to avoid increased risk of melanoma or nonmelanoma skin cancer (odds ratio [OR]: 0.44 per 5\% increased 10 -year risk) and increased risks of tuberculosis and serious infections (both ORs: 0.73 per 5\% increased 10 -year risk) and preferred once-weekly to twice-daily tablets (OR: 0.76) and weekly (OR: 0.56) or fortnightly (OR: 0.65) injections. Participants preferred avoiding treatments that may cause diarrhea or nausea in the first 2 weeks (OR: 0.87 per 5\% increase) and preferred treatments that effectively resolved plaque lesions (OR: 0.93 for each palm area still affected).

Conclusion: All attributes were significant predictors of choice. Patients' preference research complements clinical trial data by providing insight regarding the relative weight of efficacy, tolerability, and other factors for patients when making treatment choices.

Keywords: benefit, discrete choice experiment, patients' preferences, psoriasis, risk, treatment

\section{Introduction}

Psoriasis is a chronic, inflammatory disease that manifests as red, scaly plaques varying in size and symptom burden. ${ }^{1,2}$ Quality of life can be adversely affected, with both physical and psychological well-being severely affected. ${ }^{1,3,4}$ Patient self-management can be challenging, with significant comorbidities such as arthritis, metabolic syndrome, atheromatous vascular disease, diabetes, obesity, and psychosocial impairment often complicating treatment outcomes. ${ }^{5-7}$ As no cure exists, treatment is aimed at working with the patient to maximize skin clearance while minimizing risk. ${ }^{8-10} \mathrm{~A}$ dialog is usually established between the clinician and the patient to explore the patient's expectations and the range of treatment options available that suit the patient's lifestyle and attitude compared to the therapeutic benefit-risk. ${ }^{2,11}$ 
Treatment options have expanded significantly in recent years, with conventional systemic oral therapies such as methotrexate and a range of effective injectable biologic options, including antitumor necrosis factor- $\alpha$, anti-interleukin 12/23, and anti-interleukin 17 agents, now available to patients with moderate-to-severe psoriasis who are not benefiting from topical treatments or phototherapy. ${ }^{2,7,9}$ However, biologic therapy may come with a higher risk of serious infection than other therapeutic options, ${ }^{12}$ and one study found that biologic treatments are often initiated late in the treatment pathway, with a mean duration from psoriasis diagnosis to the first biologic of 22.1 years. ${ }^{13}$

Both the National Institute for Health and Care Excellence (NICE) ${ }^{2}$ and the American Academy of Dermatology ${ }^{11}$ have placed increased emphasis on patient-centric care and patients' preferences. Guidance from the latter, in particular, has moved away from systematic sequencing in favor of immediate treatment plans based on individual patient needs, placing a specific emphasis on patient education and input. ${ }^{11}$ Using the various available patient-reported outcomes measurement tools for psoriasis, ${ }^{14,15}$ there has been a shift to improve the understanding of patients' preferences and to incorporate these into the prescribing decision to improve overall therapeutic effectiveness in real-world clinical practice, especially as studies have shown considerable patient dissatisfaction with current treatment options, and a gulf has developed between patient expectations and the care they receive. ${ }^{1,16,17}$

The aim of this discrete choice experiment (DCE) was to capture the preferences of patients with moderate-to-severe psoriasis regarding different aspects of their treatment, including mode and frequency of administration, adverse event risks, and therapeutic benefit. The impact of prior treatment history and health-related quality-of-life (HRQL) status on these preferences was also evaluated. This information can help different decision makers with health technology assessment, shared decision making, and benefit-risk assessment.

\section{Methods}

\section{Study design and population}

Participants aged $\geq 18$ years with a formal psoriasis diagnosis and three or more palm areas or $\geq 3 \%$ of body surface area (BSA) affected were included. The BSA score was used because it is a relatively easy measure for patients to approximate and self-report and is recognized in clinical guidelines as a validated measure of psoriasis disease severity. ${ }^{2,18}$ All participants needed to be a resident of the
UK, have adequate fluency in English, and have access to the Internet. The recruitment of current or past recipients of biologic therapy for psoriasis was capped at $30 \%$ of the total sample. Participants with self-reported acute illness or cognitive impairment were excluded. In addition, the survey included three mathematics-based screening questions to exclude people who were unable to understand the fractions and percentages used in the questionnaire by providing two or more incorrect answers. The study was conducted in accordance with the Declaration of Helsinki and, owing to the absence of an appropriate independent review board in the UK, the study protocol was referred to and approved by the Salus Institutional Review Board in Austin, TX, USA.

\section{Survey development}

The online DCE survey was developed in line with best practice guidance..$^{19,20}$ To support the development of the survey, a brief literature review examined previous psoriasis research to evaluate the drivers of patients' preferences in psoriasis and to identify the aspects of treatment that patients and physicians value. The review also informed the identification of products currently available and their characteristics.

Two rounds of face-to-face consultation were conducted with a leading consultant dermatologist who advised on the clinical appropriateness and patient relevance of each attribute selected, in addition to the levels of each attribute.

The final selection of attributes was based on characteristics (ie, treatment delivery methods) and clinically relevant properties (ie, safety and efficacy) of available treatments for patients with moderate-to-severe psoriasis who are not benefiting from topical treatments or phototherapy. A total of six attributes with four levels each were included in the final survey (Table 1).

The attributes and levels were tested in a small pilot study $(\mathrm{N}=6)$ involving one-on-one cognitive debriefing telephone interviews. All participants provided their written informed consent for this study, and the interviews were audio recorded to aid analysis. This exercise was used to assess content validity of the DCE survey, including general comprehension, interpretation, and readability of the survey items and pictographs, and respondent burden (in terms of length and complexity of the items and the overall survey). During the interviews, participants were asked to discuss each attribute in detail to determine its relevance to treatment satisfaction. They were also asked to provide feedback on the language used in the attribute levels (ie, to interpret and explain the meaning of each attribute) and to describe the attributes in terms of importance. Content analysis was conducted on the 
Table I Treatment attributes and levels used in the discrete choice experiment

\begin{tabular}{|c|c|c|}
\hline Treatment attribute & Definition & Attribute levels \\
\hline \multirow[t]{2}{*}{ Efficacy } & BSA affected by psoriasis after using & Survey $A: 3,5,7$, or 12 palm areas \\
\hline & medication & Survey B: $2,4,6$, or 8 palm areas \\
\hline \multirow[t]{2}{*}{ Administration } & Mode of administration & I tablet/week, I tablet twice-daily, \\
\hline & & weekly injection, or fortnightly injection \\
\hline \multirow[t]{2}{*}{ Risk of diarrhea or nausea } & Increased risk of diarrhea or nausea in the & $0 \%, 5 \%, 10 \%$, or $15 \%$ \\
\hline & first 2 weeks of treatment & \\
\hline \multirow[t]{2}{*}{ Long-term risk of melanoma or NMSC } & Percentage increased risk of developing & $0 \%, 1 \%, 3 \%$, or $5 \%$ \\
\hline & melanoma or NMSC over the next 10 years & \\
\hline \multirow[t]{2}{*}{ Long-term risk of active TB } & Percentage increased risk of developing TB & $0 \%, 2 \%, 5 \%$, or $10 \%$ \\
\hline & over the next 10 years & \\
\hline \multirow[t]{3}{*}{ Long-term risk of serious infection } & Percentage increased risk of developing a & $0 \%, 10 \%, 20 \%$, or $40 \%$ \\
\hline & serious infection (eg, cellulitis, pneumonia) & \\
\hline & over next 10 years & \\
\hline
\end{tabular}

Abbreviations: BSA, body surface area; NMSC, nonmelanoma skin cancer; TB, tuberculosis.

interview data, and the survey was modified and finalized in line with the feedback obtained. The revisions were minor, and further rounds of cognitive debriefing were not deemed necessary.

\section{Treatment profiles}

Thirty-two hypothetical treatment profile pairs were created through combining the different attributes and levels. An orthogonal fractional factorial design was used to identify a minimum specification of combinations of attributes and levels that could define these hypothetical treatments. The combinations were then paired using the fold-over design outlined by Street et $\mathrm{al}^{21}$ and estimated to be $99 \%$ efficient. These design elements were specifically included to support the analysis of the choice data and ensure more accurate data outcomes. The 32 treatment profile pairs were used to create two versions of the DCE survey with 16 sets each, Survey A and Survey B, to which participants were randomly allocated. In addition, Survey A and Survey B differed in the number of hand areas of their body that participants were asked to imagine were affected by plaque psoriasis when making their treatment choices; Survey A specified 15 palm areas and Survey B specified 10.

Participants in the UK were recruited by a specialist recruitment agency to complete the DCE survey online. Participants had to first meet the eligibility criteria via a self-report online screener that confirmed if they had been diagnosed with psoriasis (Yes $=$ include), if they were currently prescribed treatment $($ Yes $=$ include/No $=$ exclude), and if they were residents of the UK (Yes $=$ include $/ \mathrm{No}=$ exclude). They were also asked to report whether they had $\geq 3 \%$ or $<3 \%$ of BSA affected by psoriasis ( $\angle 3 \%=$ exclude); this was later raised to $\geq 5 \%$ of BSA affected $(<5 \%=$ exclude $)$. The participants who were deemed eligible were directed to an online informed consent form and were asked to indicate that they had read and understood the document and agreed to participate in the online survey by ticking a box.

Participants were asked to choose between two treatment profiles consisting of combinations of attributes (Figure 1). This was preceded by full instructions on the purpose of the DCE. Participants were also asked to complete a demographic questionnaire and the Dermatology Life Quality Index (DLQI) ${ }^{14}$ to evaluate HRQL. The DLQI is scored from 0 to 30 , with a score of $0-1$ indicating that psoriasis has no effect at all on the quality of life, $2-5$ indicating a small effect, 6-10 indicating a moderate effect, 11-20 indicating a very large effect, and finally 21-30 indicating an extremely large effect. Participants were also asked to rate the extent of their psoriasis lesions in terms of hand palm areas.

\section{Statistical analysis}

The sample size was not empirically determined; the aim was to include as many participants as possible within the limits of the criteria. Originally, 300 participants were recruited for the main DCE survey. However, during data cleaning, four duplicates were identified and removed from the data set. In addition, four participants were excluded for reporting an affected BSA $<3 \%$ in the DCE, having previously passed the screener by reporting a $\mathrm{BSA} \geq 3 \%$. The survey results were therefore based on a final sample size of 292 participants.

Demographic and disease characteristics were collected and reported descriptively. Preference results from the DCE were analyzed for the overall population and stratified by DLQI score and previous biologic therapy exposure.

The DCE data from Survey A and Survey B were pooled and the efficacy attribute (BSA affected by psoriasis after 
Imagine that you have moderate-to-severe plaque psoriasis covering 10 hand palms. Which medicine would you choose if you could only choose one and these were your only options?

\begin{tabular}{|l|}
\hline \multicolumn{1}{|c|}{ Choice 17} \\
\hline $\begin{array}{l}\text { Body surface area affected by } \\
\text { psoriasis after using medication }\end{array}$ \\
\hline How you take your medication \\
\hline $\begin{array}{l}\text { Increased risk of diarrhea or } \\
\text { nausea in the first } 2 \text { weeks }\end{array}$ \\
\hline $\begin{array}{l}\text { Increased risk of melanoma or } \\
\text { nonmelanoma skin cancer in } \\
\text { the next } 10 \text { years }\end{array}$ \\
\hline $\begin{array}{l}\text { Increased risk of tuberculosis } \\
\text { in the next } 10 \text { years }\end{array}$ \\
\hline $\begin{array}{l}\text { Increased risk of serious infection, } \\
\text { for example, cellulitis (skin infection) } \\
\text { or pneumonia in the next } 10 \text { years }\end{array}$ \\
\hline
\end{tabular}

Which do you prefer?

Would you prefer this treatment more than your current treatment?

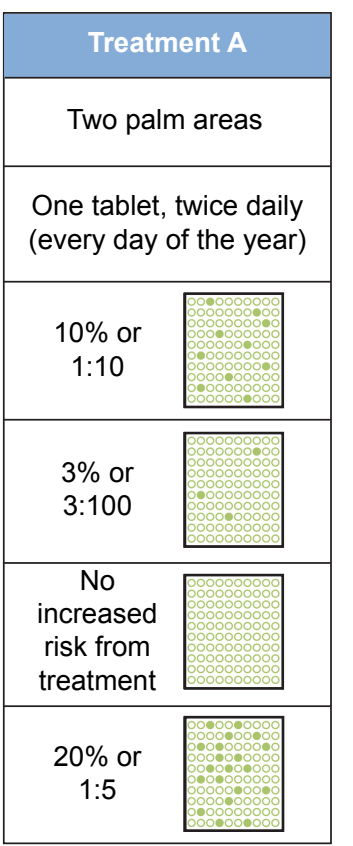

$\square$

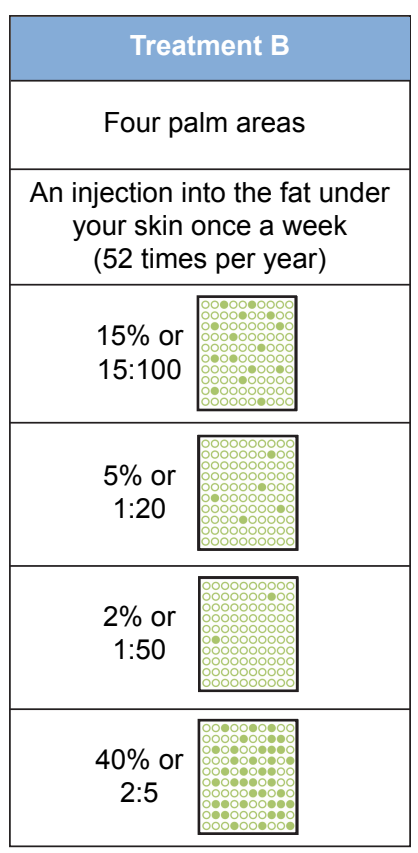

Yes/No

Figure I Example of choice sets from Survey B.

using medication) was treated as a continuous variable. The DCE data were then analyzed using a mixed effects logistic regression model. Random effects were included for all attributes to account for participants' relative preferences for specific attributes. ${ }^{22}$ The mixed effects of logistic regression model was used to generate relative preferences between hypothetical treatment profiles using the odds ratio (OR) between profiles, calculated as the ratio of exponentiated coefficients.

The results of the regression analysis are presented as untransformed preference weights and exponentiated ORs with $95 \%$ confidence intervals (CIs), which describe the relative odds of selecting a treatment across attribute levels. Regression results for BSA are expressed per palm area difference, whereas results for adverse events are expressed as per $5 \%$ increase in risk.

The primary regression analysis utilized a standard dummy coding framework for categorical variables in which the coefficients for attribute levels were compared with a single reference category. In addition, an effects-coded model was fit, in which each attribute level is compared with a weighted average of all levels. ${ }^{23}$ This analysis was conducted to allow for visual representation of preference weights and their variability across all attribute levels.

\section{Results}

\section{Patient characteristics}

In total, 292 participants with moderate-to-severe psoriasis completed the survey; key demographic and disease characteristics are reported in Table 2. The mean DLQI score was 10.5 , corresponding to relatively large disease-related quality-of-life impairment; approximately one in five participants reported little impact (score $\leq 5$ ), whereas $43 \%$ of participants reported a very large or extremely large impact (score $\geq 11$ ).

\section{Patients' preferences}

All attributes in the DCE analysis were significant $(P<0.05)$ predictors of choice, indicating that participants considered all attributes when making their choices (Table 3). Onceweekly tablets were preferred over all other treatment scheduling options, including twice-daily tablets and weekly or biweekly injections. Participants also had a strong preference for avoiding an increased risk of melanoma or nonmelanoma skin cancer (NMSC) and were less likely to choose treatments with increased risks of tuberculosis and serious infections over the next 10 years than treatments that may cause diarrhea or nausea in the first 2 weeks after initiation. The analysis also explored measures of model performance 
Table 2 Participants' demographics and treatment characteristics

\begin{tabular}{|c|c|}
\hline Characteristics & Participants ( $\mathbf{N}=\mathbf{2 9 2})$ \\
\hline Age, years, mean (SD) & $48.5(15.1)$ \\
\hline Age at diagnosis, years, mean (SD) & $35.8(18.7)$ \\
\hline Duration of psoriasis, years, mean (SD) & $12.6(16.8)$ \\
\hline \multicolumn{2}{|l|}{ Duration of psoriasis, years, $n(\%)$} \\
\hline$<10$ & $173(59.2)$ \\
\hline $10-<20$ & $42(14.4)$ \\
\hline$\geq 20$ & $77(26.4)$ \\
\hline Female, $n(\%)$ & $148(50.7)$ \\
\hline \multicolumn{2}{|l|}{ Geographical location, n (\%) } \\
\hline England & $235(80.5)$ \\
\hline Wales & $24(8.2)$ \\
\hline Scotland & $29(9.9)$ \\
\hline Northern Ireland & $4(1.4)$ \\
\hline Nails affected by psoriasis, n (\%) & $133(45.5)$ \\
\hline Scalp affected by psoriasis, n (\%) & $235(80.5)$ \\
\hline Diagnosed with psoriatic arthritis, n (\%) & $102(34.9)$ \\
\hline Previous exposure to biologic therapy, $\mathrm{n}(\%)$ & $75(25.7)$ \\
\hline Palm areas affected by psoriasis, mean (SD) & $9.4(7.2)$ \\
\hline \multicolumn{2}{|l|}{ Total palm areas affected by psoriasis, $\mathrm{n}(\%)$} \\
\hline $3-<5$ & $50(17.1)$ \\
\hline $5-<10$ & $150(5 \mid .4)$ \\
\hline $10-<15$ & $5 \mathrm{I}(17.5)$ \\
\hline$\geq 15$ & $4 \mid(14.0)$ \\
\hline DLQI score, mean (SD) & $10.5(6.6)$ \\
\hline \multicolumn{2}{|l|}{ Total DLQI score, n (\%) } \\
\hline $0-1$ & $8(2.7)$ \\
\hline $2-5$ & $70(24.0)$ \\
\hline $6-10$ & $88(30.1)$ \\
\hline $11-20$ & $95(32.5)$ \\
\hline $21-30$ & $31(10.6)$ \\
\hline \multicolumn{2}{|l|}{ Worst aspect of psoriasis to live with, $n(\%)$} \\
\hline Itching & 145 (49.7) \\
\hline Location of psoriasis & $67(22.9)$ \\
\hline Size of rash from psoriasis & $42(14.4)$ \\
\hline Pain or discomfort & $35(12.0)$ \\
\hline Poor sleep & $3(1.0)$ \\
\hline \multicolumn{2}{|l|}{ Current treatment being received, $n(\%)$} \\
\hline Orally taken tablet/capsule & $80(27.4)$ \\
\hline Subcutaneous injection & $38(13.0)$ \\
\hline Intravenous infusion & $12(4.1)$ \\
\hline Cream applied to the skin & $249(85.3)$ \\
\hline \multicolumn{2}{|l|}{ Satisfaction with current treatment, n (\%) } \\
\hline Very satisfied & $23(7.9)$ \\
\hline Somewhat satisfied & $98(33.6)$ \\
\hline Neutral or not sure & $76(26.0)$ \\
\hline Somewhat dissatisfied & $63(21.6)$ \\
\hline Very dissatisfied & $32(11.0)$ \\
\hline
\end{tabular}

Abbreviations: DLQI, Dermatology Life Quality Index; SD, standard deviation.

and goodness of fit. Both the likelihood ratio test (Chi-square: 1,246.9, $P<0.0001$ ) and Wald test (Chi-square: 677.36, $P<0.0001)$ were highly significant. Additionally, the Akaike information criterion score was also very high $(5,029.29)$, indicating high goodness of fit of the model.

When administration preferences were assessed using twice-daily tablets as the reference level in the main model, it was, as expected, preferred over weekly injections (OR: 0.74; 95\% CI: $0.60-0.91)$ and less preferred than onceweekly tablets (OR: 1.32; 95\% CI: 1.14-1.53), whereas fortnightly injections were not perceived as significantly different from having to take twice-daily tablets (OR: 0.84; 95\% CI: $0.70-1.05)$. When stratifying the same model by previous exposure to biologic therapies as part of an exploratory sensitivity analysis, biologic-naïve patients showed a preference for avoiding weekly (OR: $0.61 ; 95 \%$ CI: $0.50-0.74$ ) and fortnightly (OR: 0.80 ; 95\% CI: 0.64-0.99) injections, whereas the route of administration did not influence treatment preferences in the biologic-experienced group.

Mean preference weights and the corresponding $95 \%$ CIs are shown in Figure 2, indicating the relative magnitude of preferences across attributes. Preferences for all attributes displayed consistent trends, with participants preferring treatments with increased efficacy and decreased risk of adverse events. The most notable preferences were observed for risk of serious infection, reflected by the magnitude of the range of preference weights across attribute levels. Note that this is due to the fact that attribute levels spanned a hypothetical range up to $40 \%$ risk of serious infection, compared with a maximum risk of $10 \%-15 \%$ for other comorbidities.

\section{Patients' references: subgroup analysis}

Preference results from the DCE were analyzed by the DLQI score and previous biologic therapy exposure. The key findings from the subgroup analyses of the DCE study are reported in Table 4. The influence of patients' HRQL on their strength of preference for the attributes of psoriasis treatment was explored in patients with a DLQI score $\leq 10$ (moderate to no effect on patients' HRQL; $n=166$ ) and a DLQI score $>10$ (very large to extremely large effect on HRQL; $\mathrm{n}=126$ ). Participants with a DLQI score $>10$ placed less value on treatment efficacy (OR: 0.97; 95\% CI: 0.95-1.00), compared with those with a DLQI score $\leq 10$ (OR: 0.90; $95 \%$ CI: 0.88-0.93). These findings were mirrored in the subgroup results comparing biologic-experienced participants (OR: 0.97; 95\% CI: 0.94-1.00) with biologic-naïve participants (OR: 0.90; 95\% CI: 0.88-0.92). Participants with a DLQI score $>10$ were also more tolerant of the risk of toxicities than were those with a DLQI score $\leq 10$ (Table 4), an effect that was statistically significant $(P<0.05)$ for the attribute describing infection risk (OR: 0.79; 95\% CI: 0.76-0.81). Additionally, participants with a DLQI score $\leq 10$ had a stronger preference for avoiding injectable treatments relative to once-weekly tablets (Table 4). Preference weights for the biologic-naïve participants ( $\mathrm{n}=217$ ) show marked differences 
Table 3 Results of mixed effects logistic regression model for the main DCE in individuals with psoriasis reporting treatment preferences

\begin{tabular}{|c|c|c|c|c|}
\hline \multirow[t]{2}{*}{ Treatment attribute $^{a}$} & \multirow{2}{*}{$\begin{array}{l}\text { Estimated } \\
\text { coefficient }\end{array}$} & \multirow[t]{2}{*}{ OR } & \multicolumn{2}{|c|}{ 95\% Cl for OR } \\
\hline & & & Upper & Lower \\
\hline Body surface area (per palm area) & -0.08 & 0.93 & 0.91 & 0.94 \\
\hline Increased risk of diarrhea or nausea (per $5 \%$ increase) & -0.14 & 0.87 & 0.83 & 0.91 \\
\hline Increased risk of melanoma or NMSC (per 5\% increased 10-year risk) & -0.83 & 0.44 & 0.38 & 0.51 \\
\hline Increased risk of tuberculosis (per 5\% increased 10 -year risk) & -0.32 & 0.73 & 0.68 & 0.78 \\
\hline Increased risk of serious infection (per $5 \%$ increased 10 -year risk) & -0.31 & 0.73 & 0.72 & 0.75 \\
\hline Twice-daily tablet (relative to once-weekly tablet) & -0.28 & 0.76 & 0.65 & 0.88 \\
\hline Weekly injection (relative to once-weekly tablet) & -0.58 & 0.56 & 0.48 & 0.66 \\
\hline Fortnightly injection (relative to once-weekly tablet) & -0.43 & 0.65 & 0.56 & 0.75 \\
\hline
\end{tabular}

Note: ${ }^{a}$ All attributes significant at the $5 \%$ level.

Abbreviations: $\mathrm{Cl}$, confidence interval; DCE, discrete choice experiment; NMSC, nonmelanoma skin cancer; OR, odds ratio.

from the participants with biologic experience $(n=75)$. In participants with biologic experience, only the increased 10 -year risk of serious toxicities (ie, risk of melanoma or NMSC), tuberculosis, and serious infections were significant predictors of treatment preferences (Table 4). Biologic-naïve participants considered all attributes and placed the greatest value on treatment efficacy (OR: 0.90; 95\% CI: 0.88-0.93). They also preferred to avoid weekly and fortnightly injections compared with once-weekly tablets and to avoid the risk of all included toxicities in general (Table 4). There was some overlap between subgroups, defined by biologic therapy experience and DLQI score, with the majority of biologic-experienced patients also reporting a DLQI score $>10(60 \% ; n=45 / 75)$.

\section{Discussion}

This prospective study was designed to determine the relative value individuals diagnosed with moderate-to-severe psoriasis place on attributes of treatment for the disease. The results revealed the importance of minimizing the extent of lesions, but also the views of participants regarding the long-term risks of side effects, such as melanoma or NMSC, tuberculosis, and serious infections. The survey also assessed the importance of issues related to the convenience of taking medication either orally or by injection. These attributes represent different issues that need to be considered when making treatment choices. The preference weights from the study show how important these issues are for a sample of individuals with psoriasis in the UK.

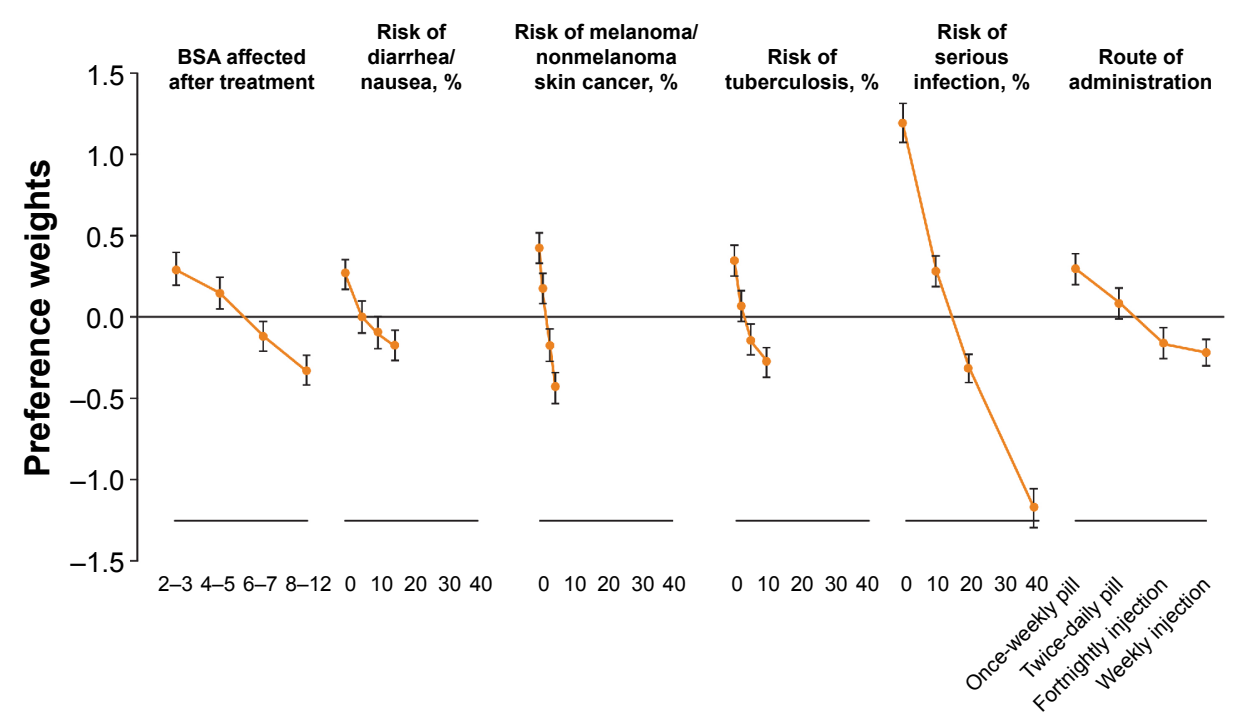

Figure 2 Preference weights (OR $>I$ vs $<1)$ and $95 \%$ confidence intervals resulting from an effects-coded discrete choice experiment in individuals with psoriasis reporting treatment preferences.

Note: The same scale was used for percentage risk of all side effect attributes.

Abbreviations: OR, odds ratio; BSA, body surface area. 
Table 4 Results of mixed effects logistic regression model for DCE in individuals with psoriasis reporting treatment preferences, stratified by subgroup

\begin{tabular}{|c|c|c|c|c|}
\hline Treatment attribute & $\begin{array}{l}\text { DLQI } \leq 10, \\
n=166, \\
\text { OR }(95 \% \mathrm{CI})\end{array}$ & $\begin{array}{l}\text { DLQI > I0, } \\
n=I 26, \\
\text { OR }(95 \% \mathrm{CI})\end{array}$ & $\begin{array}{l}\text { Biologic therapy } \\
\text { experience, } n=75 \text {, } \\
\text { OR }(95 \% \mathrm{Cl})\end{array}$ & $\begin{array}{l}\text { Biologic therapy } \\
\text { naïve, } n=2 \text { I } 7 \text {, } \\
\text { OR }(95 \% \mathrm{CI})\end{array}$ \\
\hline BSA (per palm area) & $0.90(0.88-0.93)^{\mathrm{a}}$ & $0.97(0.95-1.00)$ & $0.97(0.94-1.00)$ & $0.90(0.88-0.92)^{\mathrm{a}}$ \\
\hline Increased risk of diarrhea or nausea (per $5 \%$ increase) & $0.84(0.79-0.90)^{\mathrm{a}}$ & $0.88(0.82-0.94)^{\mathrm{a}}$ & $1.01(0.93-1.09)$ & $0.79(0.75-0.85)^{\mathrm{a}}$ \\
\hline $\begin{array}{l}\text { Increased risk of melanoma or nonmelanoma skin } \\
\text { cancer (per 5\% increased 10-year risk) }\end{array}$ & $0.43(0.35-0.53)^{\mathrm{a}}$ & $0.45(0.36-0.56)^{a}$ & $0.57(0.44-0.74)^{\mathrm{a}}$ & $0.38(0.32-0.46)^{\mathrm{a}}$ \\
\hline Increased risk of tuberculosis (per $5 \%$ increased 10 -year risk) & $0.73(0.66-0.80)^{\mathrm{a}}$ & $0.75(0.67-0.83)^{\mathrm{a}}$ & $0.85(0.75-0.97)^{\mathrm{a}}$ & $0.66(0.60-0.72)^{\mathrm{a}}$ \\
\hline Increased risk of serious infection (per $5 \%$ increased 10 -year risk) & $0.70(0.67-0.72)^{\mathrm{a}}$ & $0.79(0.76-0.81)^{\mathrm{a}}$ & $0.87(0.85-0.90)^{\mathrm{a}}$ & $0.70(0.68-0.72)^{\mathrm{a}}$ \\
\hline Twice-daily tablet (relative to once-weekly tablet) & $0.74(0.60-0.91)^{\mathrm{a}}$ & $0.75(0.6 \mathrm{I}-0.93)^{\mathrm{a}}$ & $0.79(0.6 \mathrm{I}-\mathrm{I} .02)$ & $0.71(0.59-0.85)^{\mathrm{a}}$ \\
\hline Weekly injection (relative to once-weekly tablet) & $0.48(0.39-0.61)^{\mathrm{a}}$ & $0.72(0.57-0.90)^{\mathrm{a}}$ & $0.84(0.63-1.11)$ & $0.43(0.35-0.53)^{\mathrm{a}}$ \\
\hline Fortnightly injection (relative to once-weekly tablet) & $0.49(0.40-0.60)^{\mathrm{a}}$ & $0.86(0.70-1.06)$ & $0.78(0.60-1.02)$ & $0.57(0.48-0.69)^{\mathrm{a}}$ \\
\hline
\end{tabular}

Note: a Attributes significant at the $<5 \%$ level.

Abbreviations: BSA, body surface area; Cl, confidence interval; DCE, discrete choice experiment; DLQI, Dermatology Life Quality Index; OR, odds ratio.

This research builds on the previous studies reporting patients' preferences for the treatment of psoriasis. ${ }^{24-27}$ In a recent DCE conducted in German patients with moderateto-severe psoriasis, Kromer et $\mathrm{al}^{25}$ found that the safety of biologics was the most important attribute, followed by efficacy, but preferences varied with sociodemographic characteristics and working status. These results were consistent with an earlier report by Seston et $\mathrm{al}^{27}$ who found that attributes such as adverse effects, time to improvement, and relapse time frames influence treatment choices of individuals with psoriasis. Although Seston et al found a preference for minimizing the risk of adverse events, Schaarschmidt et al, in a 2011 study ${ }^{26}$ reported that patients were willing to trade an increased risk of adverse events for better therapeutic outcomes. Unlike our study, neither study considered the previous treatment history of patients and how this might impact decision making. Schaarschmidt et $\mathrm{al}^{26}$ concluded that incorporating patients' preferences into the prescribing decision may facilitate increased adherence and lead to better treatment outcomes, a view shared by Umar et $\mathrm{al}^{28}$ whose systemic review concluded that using patients' preferences in decision making would likely improve both patient satisfaction and treatment outcomes.

In this study, participants showed a strong preference for avoiding treatments with serious long-term toxicities, such as melanoma or NMSC and serious infections, and for avoiding injectable therapies, especially if they had not previously used biologic therapies. These stated patient preferences may, in part, explain the protracted period of $>22$ years between diagnosis and initiation on biologic treatment reported by Fonia et $\mathrm{al}^{13}$ in UK clinical practice. Other factors that may affect this delay include the current reimbursement criteria in terms of disease severity and the prerequisite of the number of treatments patients must have failed before being eligible for biologic therapies in the UK. ${ }^{2,29}$ A delay in referral from primary to secondary care, general challenges in access to specialist dermatology services throughout the UK, and the high cost of biologic treatment may also play a part.

Participants who reported that their psoriasis had a very large impact on their quality of life (DLQI score $>10 ; n=126$, $43.1 \%$ ) had a higher likelihood of accepting treatment-related toxicities in relation to risk of serious infection and were less reluctant to receive injections. Overall, participants with no prior experience with biologic therapies were more averse to the risks of treatment toxicities compared with people with biologic experience. A trend was also observed for the biologic-experienced group to be more willing to accept injection treatments. This suggests that previous experience with biologic therapies or experiencing a very large effect on HRQL (DLQI score >10) may affect patients' treatment preferences by reducing aversion to injections and increasing acceptance of adverse events and reduced efficacy. These two subgroups also stated preferences that appeared to place less differentiation between the hypothetical treatment options included in the DCE and less extreme preferences for all attributes considered. The similarities between the treatment preferences seen in participants with a DLQI score $>10$ and biologic-experienced participants can be expected because the majority of biologic-experienced patients $(60 \%)$ also reported a DLQI score $>10$. Such an overlap is not surprising, given that the criteria for receiving biologic therapy in the UK include having a DLQI score $>10$. Moreover, the experience of failing on or switching between multiple therapies, including biologics, may affect patients' 
expectations of future treatment, increasing their willingness to accept treatments with different modes of administration, such as injections, and altering their benefit-risk tolerances. This may apply particularly to participants in the current DCE who reported both biologic experience and a DLQI score $>10$. These factors in combination may be an indicator of being treatment refractory due to lack of efficacy or due to toxicities, thus leaving them few treatment options to consider in real life and therefore reducing their concerns about trying hypothetical treatments with less-favorable profiles.

In addition, the analyses indicated that people with better HRQL (DLQI score $\leq 10$ ) placed more value on treatments that reduce the extent of BSA affected by psoriasis. Similar effects have been seen previously in other chronic diseases. ${ }^{30-32}$ It is possible that people who value treatments more highly are more likely to be adherent and therefore experience less disease burden. ${ }^{30}$ Longitudinal research is needed to explore these effects in more detail. These methods may be able to provide fresh insights into what drives good outcomes in psoriasis.

The regulatory environment is also becoming increasingly accepting of evidence on patients' treatment preferences during their decision-making processes. Indeed, the 2012 US Food and Drug Administration guidelines from the Center for Devices and Radiological Health on benefit-risk analysis clearly state the importance of considering patients' preferred treatment when approving medical devices to market. ${ }^{33}$ The Food and Drug Administration is also using patient feedback and preference DCE evidence to help to facilitate the development and use of patient-centric weight-loss devices for obese patients, a move away from its previous "one-sizefits-all" approach. ${ }^{34,35}$ In Belgium, DCE studies have been used to consider the importance of decision criteria among citizens with reference to reimbursement, ${ }^{36}$ whereas the US Centers for Medicare and Medicaid Services uses patient experience surveys to link Medicare payments to health care quality via its Hospital Value-Based Purchasing program. ${ }^{37}$ This has become an area of research for health technology assessment reimbursement agencies such as NICE in the UK, which has previously consulted on the use of multiple criterion decision analysis in their decision-making framework. ${ }^{38}$ A recent collaboration between Myeloma UK and NICE to examine how patients' treatment preferences can be quantitatively captured and incorporated alongside other data in decision modeling as part of the Health Technology Assessment program underscores the growing interest in understanding the impact and role of patients' treatment preferences in the decision-making process in the UK. ${ }^{39}$
Some limitations of this study should be considered. Patient self-reporting of psoriasis diagnosis and severity means there is potential room for error across patient comparisons. To best quantify the results, the number of attributes included in the survey needed to be finite. As a result, there may be other attributes that patients with moderate-to-severe psoriasis find important when choosing a treatment, but which we were not able to include. This is a constraint of the methodology. The pretest interviews supported the choice of attributes.

The choice survey is intended to simulate decisions in clinical practice, but of course it does not have the clinical or emotional consequences of actual decisions. Differences can arise between stated and actual choices. The results indicate the importance of different issues for patients, but this limitation should be considered when interpreting them. In addition, levels associated with each attribute may not reflect marketed therapies for psoriasis based on the available data. However, the dosing schedules for the injectable treatments reflected the most widely used biologic therapies for psoriasis in the UK at the time of this study. ${ }^{40}$ The subgroup analyses were univariate and need to be interpreted cautiously. They were exploratory and descriptive in nature, which may have limitations. However, they can go some way to help us understand heterogeneity in the preference data.

To avoid well-known cognitive problems with evaluating small probabilities, we defined the risk exposure as the chance of each of three serious side effects over 10 years. The actual risk of serious infection may not be linear over time, but exploring preferences for potential nonlinearities in risk exposure was beyond the scope of this study.

The population recruited in this study appeared to be representative of the general psoriasis population in the UK in terms of age, sex, and disease severity. ${ }^{41,42}$ A comparison of participants' demographics from this study shows some similarities with patients included in a prospective registry study in the UK and Ireland evaluating patients treated with biologic therapy. ${ }^{40}$ However, some notable differences included a shorter mean disease duration (12.6 vs 19.0 years) and a lower mean DLQI score (10.5 vs 18.0) in this study. It is possible that the method for recruitment resulted in some selection bias, as most participants in the DCE had moderate disease. However, population-based studies of psoriasis using electronic medical records from the Health Improvement Network, which are representative of the general population in the UK, have reported that a higher proportion of psoriasis patients have moderate ( $\sim 35 \%$, BSA: $3 \%-10 \%)$ compared 
with severe $(\sim 13 \%$, BSA $>10 \%)$ disease, ${ }^{41,42}$ which is similar to the patient population recruited for our DCE. The study did not seek to correlate preferences for treatment attributes in patients with difficult-to-treat manifestations, such as nail, scalp, or palmoplantar psoriasis.

\section{Conclusions}

This study shows the importance of patients' preferences toward the attributes of various potential treatment profiles for psoriasis and provides some insight into the extent to which people balance efficacy against risks of side effects and toxicities and even convenience issues. As regulators and reimbursement bodies begin to tangibly recognize the importance of patients' preferences, it will be important for health care professionals to be aware and communicate benefit-risk information to patients. The data from this study could be used to help communicate how patients feel about the benefits and risks of treatments for psoriasis and promote shared care in treatment decision making. In addition, analyses were able to demonstrate how the preferences varied within the study sample. Preferences varied in terms of disease impact on HRQL and also in terms of whether people had received biologic therapy previously. The results show how experience with biologic therapy can reduce patients' concerns about injection-based therapy. Many factors influence the quality of patient outcomes in chronic diseases. This type of research can complement clinical trial data by providing insight into the relative weight of efficacy, tolerability, and other factors for patients with psoriasis.

\section{Acknowledgments}

This research was funded by Celgene Ltd. The authors received editorial support in the preparation of the manuscript from Kathy Covino, $\mathrm{PhD}$, of Peloton Advantage, LLC, and from Lynette Eyb, both funded by Celgene Corporation. The authors, however, directed and are fully responsible for all content of and editorial decisions for this paper.

\section{Author contributions}

All authors contributed toward data analysis, drafting and revising the paper and agree to be accountable for all aspects of the work.

\section{Disclosure}

FM is an employee of Celgene Ltd. AK was an employee of Celgene Corporation at the time of the study. LE, APB, KMJ, $\mathrm{CP}$, and AJL report no conflicts of interest in this work.

\section{References}

1. Dubertret L, Mrowietz U, Ranki A, et al. European patient perspectives on the impact of psoriasis: the EUROPSO patient membership survey. Br J Dermatol. 2006;155(4):729-736.

2. National Institute for Health and Clinical Excellence. Psoriasis: Assessment and Management. Clinical Guideline No 153. London, UK: National Institute for Health and Clinical Excellence; 2012.

3. Choi J, Koo JY. Quality of life issues in psoriasis. J Am Acad Dermatol. 2003;49(Suppl 2):S57-S61.

4. Sampogna F, Tabolli S, Soderfeldt B, Axtelius B, Aparo U, Abeni D. Measuring quality of life of patients with different clinical types of psoriasis using the SF-36. Br J Dermatol. 2006;154(5):844-849.

5. Altobelli E, Petrocelli R, Maccarone M, et al. Risk factors of hypertension, diabetes and obesity in Italian psoriasis patients: a survey on sociodemographic characteristics, smoking habits and alcohol consumption. Eur J Dermatol. 2009;19(3):252-256.

6. Farley E, Menter A. Psoriasis: comorbidities and associations. G Ital Dermatol Venereol. 2011;146(1):9-15.

7. Menter A, Gottlieb A, Feldman SR, et al. Guidelines of care for the management of psoriasis and psoriatic arthritis: section 1. Overview of psoriasis and guidelines of care for the treatment of psoriasis with biologics. J Am Acad Dermatol. 2008;58(5):826-850.

8. Griffiths CE, Clark CM, Chalmers RJ, Li Wan Po A, Williams HC. A systematic review of treatments for severe psoriasis. Health Technol Assess. 2000;4(40):1-125.

9. Nickoloff BJ, Nestle FO. Recent insights into the immunopathogenesis of psoriasis provide new therapeutic opportunities. J Clin Invest. 2004; 113(12):1664-1675.

10. Pathirana D, Ormerod AD, Saiag P, et al. European S3-guidelines on the systemic treatment of psoriasis vulgaris. J Eur Acad Dermatol Venereol. 2009;23(Suppl 2):1-70.

11. Menter A, Korman NJ, Elmets CA, et al. Guidelines of care for the management of psoriasis and psoriatic arthritis: section 6. Guidelines of care for the treatment of psoriasis and psoriatic arthritis: case-based presentations and evidence-based conclusions. J Am Acad Dermatol. 2011;65(1):137-174.

12. Kalb RE, Fiorentino DF, Lebwohl MG, et al. Risk of serious infection with biologic and systemic treatment of psoriasis: results from the Psoriasis Longitudinal Assessment and Registry (PSOLAR). JAMA Dermatol. 2015;151(9):961-969.

13. Fonia A, Jackson K, Lereun C, Grant DM, Barker JN, Smith CH. A retrospective cohort study of the impact of biologic therapy initiation on medical resource use and costs in patients with moderate to severe psoriasis. Br J Dermatol. 2010;163(4):807-816.

14. Finlay AY, Khan GK. Dermatology Life Quality Index (DLQI) a simple practical measure for routine clinical use. Clin Exp Dermatol. 1994;19(3):210-216.

15. Kitchen H, Cordingley L, Young H, Griffiths CE, Bundy C. Patientreported outcome measures in psoriasis: the good, the bad and the missing! Br J Dermatol. 2015;172(5):1210-1221.

16. Lebwohl MG, Bachelez H, Barker J, et al. Patient perspectives in the management of psoriasis: results from the population-based multinational assessment of psoriasis and psoriatic arthritis survey. $\mathrm{J} \mathrm{Am} \mathrm{Acad}$ Dermatol. 2014;70(5):871-881.

17. Stern RS, Nijsten T, Feldman SR, Margolis DJ, Rolstad T. Psoriasis is common, carries a substantial burden even when not extensive, and is associated with widespread treatment dissatisfaction. $J$ Investig Dermatol Symp Proc. 2004;9(2):136-139.

18. Smith CH, Anstey AV, Barker JN, et al. British Association of Dermatologists' guidelines for biologic interventions for psoriasis 2009 . Br J Dermatol. 2009;161(5):987-1019.

19. Bridges JF, Hauber AB, Marshall D, et al. Conjoint analysis applications in health - a checklist: a report of the ISPOR good research practices for conjoint analysis task force. Value Health. 2011;14(4):403-413.

20. Reed Johnson F, Lancsar E, Marshall D, et al. Constructing experimental designs for discrete-choice experiments: report of the ISPOR conjoint analysis experimental design good research practices task force. Value Health. 2013;16(1):3-13. 
21. Street DJ, Burgess L, Louviere JJ. Quick and easy choice sets: constructing optimal and nearly optimal stated choice experiments. Int $J$ Res Mark. 2005;22(4):459-470.

22. Lancsar E, Louviere J. Conducting discrete choice experiments to inform healthcare decision making: a user's guide. Pharmacoeconomics. 2008;26(8):661-677.

23. Bech M, Gyrd-Hansen D. Effects coding in discrete choice experiments. Health Econ. 2005;14(10):1079-1083.

24. Kauf TL, Yang JC, Kimball AB, et al. Psoriasis patients' willingness to accept side-effect risks for improved treatment efficacy. J Dermatolog Treat. 2015;26(6):507-513.

25. Kromer C, Schaarschmidt ML, Schmieder A, Herr R, Goerdt S, Peitsch WK. Patient preferences for treatment of psoriasis with biologicals: a discrete choice experiment. PLoS One. 2015;10(6): e0129120.

26. Schaarschmidt ML, Schmieder A, Umar N, et al. Patient preferences for psoriasis treatments: process characteristics can outweigh outcome attributes. Arch Dermatol. 2011;147(11):1285-1294.

27. Seston EM, Ashcroft DM, Griffiths CE. Balancing the benefits and risks of drug treatment: a stated-preference, discrete choice experiment with patients with psoriasis. Arch Dermatol. 2007;143(9):1175-1179.

28. Umar N, Yamamoto S, Loerbroks A, Terris D. Elicitation and use of patients' preferences in the treatment of psoriasis: a systematic review. Acta Derm Venereol. 2012;92(4):341-346.

29. National Institute for Health and Care Excellence. NICE pathways: Psoriasis overview; 2016. Available from: https://pathways.nice.org. uk/pathways/psoriasis. Accessed November 21, 2016.

30. Hodgkins P, Swinburn P, Solomon D, Yen L, Dewilde S, Lloyd A. Patient preferences for first-line oral treatment for mild-to-moderate ulcerative colitis: a discrete-choice experiment. Patient. 2012;5(1):33-44.

31. Lloyd A, McIntosh E, Price M. The importance of drug adverse effects compared with seizure control for people with epilepsy: a discrete choice experiment. Pharmacoeconomics. 2005;23(11):1167-1181.

32. Lloyd A, McIntosh E, Williams AE, Kaptein A, Rabe KF. How does patients' quality of life guide their preferences regarding aspects of asthma therapy? A patient-preference study using discrete-choice experiment methodology. Patient. 2008;1(4):309-316.
33. Center for Devices and Radiological Health. Factors to consider when making benefit-risk determinations in medical device premarket approval and de novo classifications; 2012. Available from: http://www. fda.gov/downloads/MedicalDevices/DeviceRegulationandGuidance/ GuidanceDocuments/UCM296379.pdf. Accessed June 8, 2016.

34. Ho MP, Gonzalez JM, Lerner HP, et al. Incorporating patient-preference evidence into regulatory decision making. Surg Endosc. 2015;29(10): 2984-2993.

35. Lerner H, Whang J, Nipper R. Benefit-risk paradigm for clinical trial design of obesity devices: FDA proposal. Surg Endosc. 2013;27(3): 702-707.

36. Cleemput I, Devriese S, Kohn L, et al. Incorporating societal preferences in reimbursement decisions - relative importance of decision criteria according to Belgian citizens; 2014. Available from: https://kce.fgov.be/sites/default/files/page_documents/ KCE_234_reimbursement_decisions_Report_0.pdf. Accessed June 8, 2016.

37. Centers for Medicare and Medicaid Services. Medicare program; hospital inpatient value-based purchasing program. Final rule. Fed Regist. 2011; 76(88):26490-26547.

38. Thokala P, Duenas A. Multiple criteria decision analysis for health technology assessment. Value Health. 2012;15(8):1172-1181.

39. Underwood G. NICE to research patient preferences in HTA; 2016. Available from: http://www.pharmatimes.com/news/nice_to_research_ patient_preferences_in_hta_1033029. Accessed June 8, 2016.

40. Iskandar IY, Ashcroft DM, Warren RB, et al. Demographics and disease characteristics of patients with psoriasis enrolled in the British association of dermatologists biologic interventions register. Br J Dermatol. 2015;173(2):510-518.

41. Yeung H, Takeshita J, Mehta NN, et al. Psoriasis severity and the prevalence of major medical comorbidity: a population-based study. JAMA Dermatol. 2013;149(10):1173-1179.

42. Takeshita J, Wang S, Shin DB, et al. Effect of psoriasis severity on hypertension control: a population-based study in the United Kingdom. JAMA Dermatol. 2015;151(2):161-169.
Patient Preference and Adherence

\section{Publish your work in this journal}

Patient Preference and Adherence is an international, peer-reviewed, open access journal that focuses on the growing importance of patient preference and adherence throughout the therapeutic continuum. Patient satisfaction, acceptability, quality of life, compliance, persistence and their role in developing new therapeutic modalities and compounds to optimize

\section{Dovepress}

clinical outcomes for existing disease states are major areas of interest for the journal. This journal has been accepted for indexing on PubMed Central. The manuscript management system is completely online and includes a very quick and fair peer-review system, which is all easy to use. Visit http://www. dovepress.com/testimonials.php to read real quotes from published authors. 